\title{
Knowing who I am depends on who I've become: Linking self-concept clarity and temporal self-comparison
}

\author{
Samantha Zaw \\ University of Florida
}

\author{
Matthew Baldwin \\ University of Florida
}

\begin{abstract}
The current research examined how temporal self-comparisons influence self-concept clarity. In Studies 1 and 2, we updated and developed new measures of state self-concept clarity, including specific components identified in prior research. In both studies, participants' confidence in their judgments, as well as the consistency of those judgments, was associated with the self-reported state self-concept clarity. Using the new measures, Study 3 found that selfconcept clarity was highest when participants engaged in temporal comparisons that focused on positive similarities between their past and present selves and when comparisons highlighted improvement over time. These findings suggest that self-concept clarity is an emergent phenomenon that arises from comparison-based self-evaluations that fit common lay theories about how the self develops over time.
\end{abstract}

Keywords: self-concept, self-concept clarity, temporal comparison, temporal-self appraisal, self and identity

\section{Introduction}

"Who am I?" is a question that has confronted humankind as early as there are records of humans' dealings with each other, the meaning of life, and their experiences in the world (Smith, 2010; Taylor et al., 1996). The extent to which one finds a satisfactory answer to this question likely imparts psychological benefits to the individual. Contemporary social psychology has shown, for instance, that a sense of authenticity (Ryff, 1989), positive social identity (Jetten et al., 2017; Jetten et al., 2012; Sharma and Sharma, 2010), and a clear sense of who one is (Campbell et al., 1996), are all associated with psychological well-being. Considering that knowing oneself has such clear benefits, it is important to understand the psychological processes that are involved in people's search for themselves.

In the current research, we examine the role of temporal comparison-how comparing oneself across time-gives people clarity on who they are. Although it is wellunderstood that the self-concept has a temporal dimension (see Albert, 1977; McAdams, 2008; McAdams and McLean, 2013; McAdams and Pals, 2006), research on self-concept clarity (Campbell et al., 1996) has yet to fully integrate this dimension in theorizing about how people come to find clarity in who they are. That is, it is not well understood how

Matthew Baldwin (1) https://orcid.org/0000-0002-7355-478X

Address Correspondence to: Matthew Baldwin, 524 McCarty Hall C, Department of Psychology, University of Florida, Gainesville, FL, 32603, mbaldwin1@ufl.edu, 352-328-2494 individuals' evaluations of themselves at different points in time affect the clarity of their self-concepts. This research aims to address this gap. We start with a review of the temporal comparison literature and then transition to hypothesize how temporal comparisons may affect self-concept clarity.

\section{Temporal Self-Comparison}

Comparison is a building block of human social life (Festinger, 1954), and humans may be unique in their ability to compare themselves across time (Suddendorf and Busby, 2003). People have the unique ability to develop life narratives that integrate who they were, who they are, and who they will become in the future (McAdams and McLean, 2013; Ricoeur, 1991). This means that deciding who one is today depends to some degree on who one was yesterday (Albert, 1977) or will be tomorrow (Markus and Nurius, 1987; Ryff, 1991). Comparing oneself today to versions of oneself in the past and future helps us gain information about the self that is relevant for judgments of our abilities, attributes, character, and trajectory in life.

Research has shown that temporal comparisons can serve a positive function for the self. For instance, Albert (1977) translated Festinger's (1954) social comparison theory to develop a model of temporal comparison with a primary focus on the nature and consequences of comparing the present self to the past self. Albert was primarily interested in the extent to which temporal comparisons help to maintain an enduring, coherent, and integrated identity over time. This idea is supported by research showing that life stories help people create coherent wholes out of disparate life events (Bluck et al., 2005). Other research shows that people are motivated 
to pursue goals that bring the present closer to the future self especially in the face of events that disrupt that continuity (Peetz and Wilson, 2013). People may also engage in specific past self comparisons when faced with discontinuity: For example, people report feeling more nostalgic when self-continuity is threatened, and recalling nostalgic memories can promote self-continuity in the face of those threats (Sedikides et al., 2016).

Sometimes temporal comparisons serve to put distance between the present and the salient temporal comparison standard (i.e., a contrast effect). When comparing to past and future selves, people tend to treat those selves as "others" and exhibit typical actor-observer effects when evaluating those selves (Pronin and Ross, 2006). Often times, these kinds of comparisons serve to bolster the present self by allowing people to see ways that they have changed (or will change) for the better. This particular self-evaluation has now been covered extensively by temporal self-appraisal theory (M. Ross and Wilson, 2000, 2003; A. E. Wilson and Ross, 2000, 2001), which proposes that people self-enhance by disparaging distant past-selves who have little bearing on the present self. Even when no actual improvement has occurred, people seem to distance from past-selves, disparage them, then arrive at a belief that they have changed for the better (A. E. Wilson and Ross, 2001). In fact, people have an implicit belief, or lay theory, that they will change for the better (O'Brien and Kardas, 2016), which fits with the prevalence of the redemptive narrative in life stories (McAdams, 2001) and research on the fresh start effect, in which people construe turning points in life as a break from the negative past self, and a chance to live a better life in the future (Dai and $\mathrm{Li}, 2019$ ).

Taken together, these findings suggest that people use both similarity and difference judgments to evaluate who they are as an unfolding temporal self. A recent set of studies tested this full range of possible comparisons between the past and present selves based on differences and similarities (2021). This research applied a cognitive-ecological model of comparison known as the Evaluative Information Ecology model (EvIE; Alves et al., 2017b) which suggests that similarity judgments often result in positive evaluations because positive attributes are more likely to be shared among people and objects, whereas difference judgments typically result in negative evaluations because negative attributes tend to be unique among people and objects. However, when these comparisons play out for the temporal self, an evaluative asymmetry emerges such that most comparisons lead to positive evaluations of the self being evaluated, with one exception. When people are focused on the way that the past self was different from the present self, these past differences are typically evaluated as more negative than all other comparisons. In other words, unique characteristics of the present self (vs. the past self) and shared features between the past and present selves are typically rated positively, but unique aspects of the past self are evaluated more negatively. These findings suggest that lay theories about positive change over time (McAdams and McLean, 2013; O'Brien and Kardas, 2016) and about positive stability over time (Albert, 1977; Peetz and Wilson, 2013) may have a basis in basic cognitive processes that are played out in an information ecology that favors the stability and growth of positive attributes (see 2021).

Thus, it is possible that people use the information they receive from temporal comparisons to examine whether or not their lives fit their lay theories about how they should be changing, or remaining stable, over time. If this is true, then people should feel more clear about who they are when the evaluative outcome of their temporal comparisons matches these temporal trajectories of the self. When people become aware that their negative attributes are unique to their past selves, lay theories of improvement are supported. When people learn that their positive attributes are shared between their past and present selves, lay theories of positive continuity are supported. We hypothesize that these evaluations will influence individuals' self-concept clarity. In the next section, we briefly describe the literature on self-concept clarity and elaborate on this hypothesis.

\section{Linking Self-Concept Clarity and Temporal Self-Comparison}

Self-concept clarity is the degree to which the self-concept is clearly and confidently defined (Campbell, 1990), temporally stable, and internally consistent (Campbell et al., 1996). The study of this construct applies a structural approach to the self, which is concerned with how the contents of one's self-concept (e.g., attributes) are perceived, organized, and evaluated. People need not be accurate about their selfconcepts to exhibit self-concept clarity, so long as those concepts are accessible, consistent, and stable, and that people feel confident and clear about who they are. These ideas are supported by data suggesting that people who self-report high levels of self-concept clarity also express less ambivalent attitudes about their self-attributes, they feel more confident in their self-evaluations, and the attributes that they ascribe to themselves are more consistent with one another, and more stable over time (1996). Self-concept clarity is thus seen as a resource that is intrinsic to the person, or a "self-opinion" that endures despite some susceptibility to situational influence (1996). This approach has led to a view that self-concept clarity develops alongside other dispositions, such as personality (e.g., neuroticism), chronic self-reflection, rumination, cultural self-construal, and selfesteem (1996). Altogether, the evidence suggests that knowing who one truly is, without confusion or conflict and with some degree of stability, can be a positive resource for the self. 
However, despite this strong foundational research, we feel that the theory of self-concept clarity is lacking in one crucial way: namely, in fully explaining the mechanism that gives rise to self-concept clarity. The most robust association found in the literature is between high self-clarity and high self-esteem, but why could someone with low self-esteem be unclear about what may be a more negative self-concept? Indeed, someone may hold a negative self-view and feel very certain about it. Other findings suggest small associations with variables such as neuroticism and the tendency to ruminate, or an inquisitive attitude toward oneself (self-reflection; Campbell et al., 1996). Nevertheless, why should these variables specifically provide more or less clarity about oneself? The theory is unclear on such questions.

To help address this limitation, we propose that a cognitive-ecological approach (Unkelbach et al., 2019) can provide some insight on how self-concept clarity arises as an emergent property of relative self-judgments in a known information ecology (see also 2021). We start with the premise that whenever information is perceived, processed, or evaluated, it is almost inevitably compared to an available standard Kahneman and Miller, 1986). Thus, when people (or participants in a study) have to make a judgment about themselves on a relevant trait or attribute, or simply respond to a scale item about their confidence in who they are, they will very likely engage in a self-comparison in order to make this judgment. When assessing whether one is "respectful," for instance, one might look back to a former self for evidence of being a respectful person.

When will this self-comparison result in high versus low self-concept clarity? Simply put, we suggest that clarity comes when the result of the comparison fits what would be expected given the statistical properties of the information ecology, and the given common lay theories about how people change or remain the same over time. Here we focus on two expectations that can have this effect. First, when a comparison highlights similarities, those similarities will be positive. This outcome occurs because there is more positive information (vs. negative information) in the world and thus, positive information is more likely to be shared among people and objects (i.e., the common good phenomenon; Alves et al., 2017a; Unkelbach et al., 2019). The link between shared information and positive information can also be reversed: Evaluations that focus on positive attributes will also highlight similarities among targets being evaluated. Thus, when people who hold positive self-views have to evaluate their attributes, it is statistically likely that they will engage in self-comparisons that highlight similarities across time. Self-comparisons based on positive similarities likely result in high self-clarity because this particular comparison confirms what is to be expected given the way information is distributed in the world and across time, and it likely fits people's theories about the way positive attributes should re- main stable over time (Molouki and Bartels, 2017; Zhang and Chen, 2018).

A second expectation following from the cognitiveecological approach is that comparisons based on differences should produce positive evaluations of the present self, by either highlighting uniquely negative past self attributes, or uniquely positive present self attributes (Baldwin et al., 2021; A. E. Wilson and Ross, 2001). This outcome occurs because of a so-called growth principle in which positive attributes tend to be reinforced over time, whereas negative attributes tend to be punished or corrected (2021). The link between a difference focus and perceptions of growth can also be reversed: When focused on positive attributes, people will be more likely to assign them uniquely to the present self, but when focused on negative attributes, people will likely assign them uniquely to the past self. Again, people with chronically positive self-views not only have the advantage of finding positive similarities over time, but also likely posses many uniquely positive attributes in the present, which highlights growth and improvement. Because people expect positive change over time (O'Brien and Kardas, 2016), this kind of discontinuity is non-disruptive (Molouki and Bartels, 2017) and when confirmed through temporal comparison, should give rise to self-concept clarity.

In sum, we propose that self-concept clarity is not necessarily a resource intrinsic to an individual, but is rather the feeling that arises when self-evaluations match how people expect the self to develop over time. When those expectations are not met, we expect self-concept clarity to be low.

\section{The Present Research}

Our primary aim in this research is to examine the link between temporal comparison, or the act of comparing similarities and differences between the past and present selves, and self-concept clarity. However, given that we are interested in momentary feeling of clarity following a real-time comparison, we felt it necessary to further develop a state measure of self-concept clarity. In Part One, Studies 1 and 2 create a state self-concept clarity scale as well as update an indirect measure of three components of self-clarity identified in past research, namely, consistency, accessibility, and confidence of self-attribute judgments (Campbell et al., 1996). We were particularly interested in validating these measures by examining inter-correlations among them, as well with an established trait self-concept clarity scale. In Part Two, Study 3 tests the link between temporal comparison and self-concept clarity using the newly developed state self-concept clarity measures.

All data, materials, and analysis code can be found at https:/osf.io/vume3/?view_only= a710851d4c2e407bb0397a4fc1834b8f. 


\section{Part One: Operationalizing Self-Concept Clarity}

\section{Study 1: Self-Concept Clarity Scale Development}

Study 1 validated a measure for self-concept clarity which taps into consistency, accessibility, and confidence by revising the me/not me procedures from prior research (Campbell, 1990) using a newly validated set of attributes (more details to follow). Additionally, we developed a new 10-item scale to measure state self-concept clarity, as the most widely used scale currently measures trait self-concept clarity. Items were designed to capture each component of consistency, accessibility, and confidence in one's self-concept. In this study, we explored two competing hypotheses. One prediction is that participants with greater levels of self-concept clarity have high consistency, faster response time, and high confidence in their answers. On the other hand, it is also possible that participants with high self-concept clarity may hold inconsistent views about themselves and feel certain about possessing both opposite traits, and this may result in high confidence and quick response times but low consistency. Study 1 was preregistered at https://osf.io/vume3/?view_ only $=\mathrm{a} 710851 \mathrm{~d} 4 \mathrm{c} 2 \mathrm{e} 407 \mathrm{bb} 0397 \mathrm{a} 4 \mathrm{fc} 1834 \mathrm{~b} 8 \mathrm{f}$. This and all subsequent studies were ethics approved by the IRB at the authors' institution (IRB202000447).

\section{Method \\ Participants and design}

The study was conducted on 405 native English-speaking adults $\left(M_{\text {age }}=32.24, S D_{\text {age }}=11.91,46 \%\right.$ male $)$ across the United States on Prolific Academic for at least minimum wage. After providing consent, participants completed the $\mathrm{me} /$ not me task and self-report measures of self-concept clarity.

\section{Measures}

Participants first completed the me/not me task to assess the consistency, accessibility, and confidence components of self-concept clarity. The task instructed participants to indicate whether a set of previously validated 40 traits described them. Traits had been previously validated as being those common to most people, and consisted of 20 pairs of opposites (e.g., selfish/altruistic, negligent/caring, unreliable/trustworthy; H. Alves, personal communication, June 19, 2020). Each trait was shown separately in the center of the screen, and participants selected an option for each trait as "me" or "not me" using their mouse.

To calculate the consistency component of self-concept clarity, we first computed the total number of consistent responses as the number of times participants selected "me" for an attribute and "not me" for its opposite. We then computed the total number of inconsistent responses as the total times participants selected "me" for an attribute and "me" for its opposite. Finally, we computed non-applicable responses as the total times participants selected "not me" for both an attribute and its opposite. Consistency was calculated as the ratio of consistent responses to the sum of consistent and inconsistent responses $(M=0.83, S D=0.16)$. Accessibility was calculated as the average response time for all me/not me selections $(M=3.23, S D=7.05, \alpha=0.46)$. Finally, for each selection, participants rated their confidence in their choice $(1=$ none at all; $5=$ a great deal, and confidence was calculated as the average rating for all attributes $(M=3.82$, $S D=0.53, \alpha=0.94$ ).

After completing the me/not me task, participants responded to items on both a trait and state self-concept clarity scale. Trait self-concept clarity was measured with a 12 -item scale (Campbell et al., 1996; e.g., "My beliefs about myself often conflict with one another") using a 5-point scale $(1=$ strongly disagree; $5=$ strongly agree; $M=3.26, S D=0.95$, $\alpha=.92$ ). State self-concept clarity was measured with ten items that captured the components of accessibility, consistency, and confidence and assessed how participants were feeling in the moment (e.g., "Right now, I feel like all of my self-aspects are one consistent whole"). Participants responded using a 5 -point scale $(1=$ strongly disagree; $5=$ strongly agree; $M=3.37, S D=0.88, \alpha=0.90$ ). After completing the tasks, participants read a debriefing statement and exited the study.

\section{Results}

Thirteen participants were excluded from the data analyses for failing the attention checks. Therefore, the trimmed sample consisted of 392 participants $\left(M_{\text {age }}=32.15, S D_{\text {age }}=\right.$ $11.88,46 \%$ male).

\section{Correlations}

We initially examined correlations among all focal variables. As expected, there was a strong correlation between trait and state self-concept clarity $(p<.001)$, indicating high convergent validity of each scale. Both trait and state selfconcept clarity were correlated with confidence and consistency $(p s<.001)$; however, trait self-concept clarity had a stronger association with consistency, whereas state selfconcept clarity had a stronger association with confidence. Accessibility was virtually uncorrelated with the other variables, and therefore subsequent analyses ignore this variable. The correlations are depicted in Figure 1:

\section{Regressions}

Next, we examined the independent effects of confidence and consistency on both trait and state self-concept clarity using hierarchical regression analyses. The linear model predicting trait self-concept clarity with confidence and consistency was significant $(F(2,389)=45.22, p<.001)$, and both confidence and consistency were significant predictors (see Table 1). In step two of this model, we included state self-concept clarity as a third predictor to determine if confidence and consistency explained unique variance over state self-concept clarity. The model was significant, and adding state self-concept clarity increased model fit to a large degree $(F(3,388)=316.16, p<.001)$. As expected, state self- 


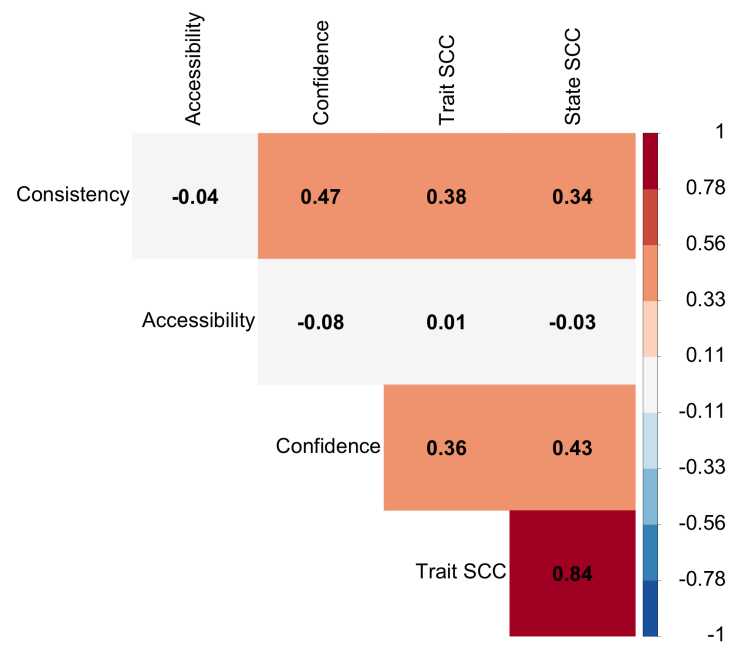

\section{Figure 1}

Study 1: Both state and trait self-concept clarity (SCC) were associated with confidence and consistency of me/not me trait judgments. Accessibility was not significantly associated with any variables.

concept clarity was a strong predictor of trait self-concept clarity, but even after controlling for this association, the effect of consistency on trait self-concept clarity remained significant. The effect of confidence was no longer significant (Table 1).

The same analyses were conducted on state self-concept clarity as the outcome. The model in step one was significant $(F(2,389)=51.22, p<.001)$, and confidence and consistency were both significant predictors (Table 1). In step two of this model, we included trait self-concept clarity as a third predictor to determine if confidence and consistency explained unique variance over trait self-concept clarity. The model was significant, and adding trait self-concept clarity increased model fit to a large degree $(F(3,388)=327.31$, $p<.001)$. As expected, trait self-concept clarity was a strong predictor of state self-concept clarity, but even after controlling for this association, the effect of confidence on trait self-concept clarity remained significant. The effect of consistency was no longer significant (Table 1).

\section{Discussion}

Study 1 reveals that self-concept clarity can be assessed with our indirect measure of both confidence and consistency of trait judgments in a me/not me task. However, associations with these two components of self-concept clarity vary between the trait and state measures. In our full regression models, trait self-concept clarity was more strongly associated with consistency of me/not me judgments, whereas state self-concept clarity was associated with self-reported confidence in those judgments. This finding suggests that trait self-concept clarity may be tied more closely to an evaluative component of the self, which includes recognizing conflicting and (non)conflicting self-attributes that define who one is. On the other hand, state self-concept clarity may reflect an affective component of the self, which includes a momentary feeling of knowing (or not) the attributes that define who one is. These results partially confirm our hypothesis that participants with high self-concept clarity will provide consistent responses with confidence.

Although past findings suggest that self-concept clarity is related to accessibility of self-relevant information (e.g., attributes, characteristics; Campbell, 1990), we were unable to find evidence supporting this notion. Accessibility was not correlated with any of our self-concept clarity measures, and the data does not support the accessibility component of our hypothesis. A potential reason for this lack of evidence may be that although most participants made a selection within a few seconds on the me/not me task, some participants took much longer to make a selection (even as long as two minutes). Thus, the high variability in selection times may contribute to the unreliability of this accessibility measure. To address this limitation, and to attempt to replicate the patterns of associations found in the regression analyses in Study 1, we conducted a second study.

\section{Study 2: Replication with Improvement}

To address the potential timing issue in Study 1, we conducted a direct replication study only with time constraints set on the me/not me task. Specifically, in Study 2, we included a $3 \mathrm{~s}$ timer for each of the 40 attributes in the me/not me task in order to encourage participants to make a quick decision.

\section{Method \\ Participants and design}

The study was conducted on 250 native English-speaking adults $\left(M_{\text {age }}=32.74, S D_{\text {age }}=11.39,45 \%\right.$ male $)$ across the United States on Prolific Academic for at least minimum wage. The procedures were identical as Study 1 except that participants were instructed to answer whether the traits described them in three seconds (vs. without a time limit).

\section{Measures}

Participants initially performed the me/not me task to assess the consistency, accessibility, and confidence components of self-concept clarity. Consistency was calculated as the ratio of consistent responses to the sum of consistent and inconsistent responses. As in Study 1, participants were mostly consistent in their responses $(M=0.84, S D=0.16)$. Accessibility was calculated as the average response time for all me/not me selections, and this measure was more reliable with the 3 s timer $(M=1.44, S D=0.30, \alpha=0.89)$. Lastly, confidence was calculated as the average rating of confidence for all attributes using a 5-point scale $(1=$ none at all; $5=$ a great deal), and confidence remained reliable $(M=3.81$, $S D=0.52, \alpha=0.93$ ). 
Table 1

Study 1: Regression Coefficients and Significant Tests for Hierarchical Regressions Predicting Self-Concept Clarity (SCC)

\begin{tabular}{|c|c|c|c|c|c|c|c|c|c|c|}
\hline Outcome & Model & $R^{2}$ & Predictor & $\beta$ & $\begin{array}{c}\beta \\
95 \% \mathrm{CI}\end{array}$ & $b$ & $S E$ & $\begin{array}{c}b \\
95 \% \mathrm{CI}\end{array}$ & $t$ & $p$ \\
\hline \multirow[t]{9}{*}{ Trait SCC } & Model 1 & 0.19 & & & & & & & & \\
\hline & & & Intercept & & & 0.27 & 0.33 & {$[-0.38,0.92]$} & & \\
\hline & & & Confidence & 0.24 & {$[0.14,0.34]$} & 0.43 & 0.09 & {$[0.25,0.61]$} & 4.60 & $<.001$ \\
\hline & & & Consistency & 0.27 & {$[0.17,0.37]$} & 1.63 & 0.32 & {$[1.01,2.25]$} & 5.17 & $<.001$ \\
\hline & Model 2 & 0.71 & & & & & & & & \\
\hline & & & Intercept & & & -0.05 & 0.20 & $[-0.44,0.34]]$ & & \\
\hline & & & Confidence & -0.04 & {$[0.10,0.02]$} & -0.07 & 0.06 & {$[-0.19,0.04]$} & -1.23 & .220 \\
\hline & & & Consistency & 0.12 & {$[0.06,0.18]$} & 0.74 & 0.19 & {$[0.36,1.12]$} & 3.87 & $<.001$ \\
\hline & & & State SCC & 0.81 & {$[0.75,0.87]$} & 0.88 & 0.03 & {$[0.82,0.95]$} & 26.39 & $<.001$ \\
\hline \multirow[t]{9}{*}{ State SCC } & Model 1 & 0.21 & & & & & & & & \\
\hline & & & Intercept & & & 0.36 & 0.30 & {$[-0.23,0.95]$} & & \\
\hline & & & Confidence & 0.34 & {$[0.24,0.44]$} & 0.57 & 0.08 & {$[0.40,0.74]$} & 6.71 & $<.001$ \\
\hline & & & Consistency & 0.18 & {$[0.08,0.28]$} & 1.00 & 0.29 & {$[0.45,1.57]$} & 3.52 & $<.001$ \\
\hline & Model 2 & 0.72 & & & & & & & & \\
\hline & & & Intercept & & & 0.17 & 0.18 & {$[-0.19,0.52]$} & & \\
\hline & & & Confidence & 0.15 & {$[0.09,0.22]$} & 0.26 & 0.05 & {$[0.15,0.36]$} & 4.92 & $<.001$ \\
\hline & & & Consistency & -0.03 & {$[-0.09,0.03]$} & -0.18 & 0.18 & {$[-0.53,0.17]$} & -1.00 & .312 \\
\hline & & & Trait SCC & 0.79 & {$[0.73,0.85]$} & 0.73 & 0.03 & {$[0.73,0.85]$} & 26.39 & $<.001$ \\
\hline
\end{tabular}

Identical to Study 1, participants responded to items on both a trait and state self-concept clarity scale after completing the me/not me task. Trait self-concept clarity was measured with a 12-item scale (Campbell et al., 1996) using a 5-point scale $(1=$ strongly disagree; $5=$ strongly agree; $M=3.19, S D=0.84, \alpha=0.90)$. Additionally, state selfconcept clarity was measured with a 10 -item scale that captured the components of accessibility, consistency, and confidence. Participants responded using a 5-point scale $(1=$ strongly disagree; $5=$ strongly agree; $M=3.39, S D=0.81$, $\alpha=0.89$ ). After completing the tasks, participants read a debriefing statement and exited the study.

\section{Results}

Eleven participants were excluded from the data analyses for failing the attention checks. Therefore, the trimmed sample consisted of 239 participants $\left(M_{\text {age }}=32.73, S D_{\text {age }}=\right.$ $11.45,45 \%$ male).

\section{Correlations}

As in Study 1, we first examined correlations among all focal variables. As expected, there was a strong correlation between trait and state self-concept clarity $(p<.001)$, indicating high convergent validity of each scale once again. Both trait and state self-concept clarity were correlated with confidence and consistency ( $p s<.001$ ); however, trait selfconcept clarity had a stronger association with consistency, while state self-concept clarity had a stronger association with confidence. Although we implemented the 3s timer, accessibility was remained weakly correlated with the other variables, and therefore subsequent analyses exclude accessibility. The correlations are depicted in Figure 2:

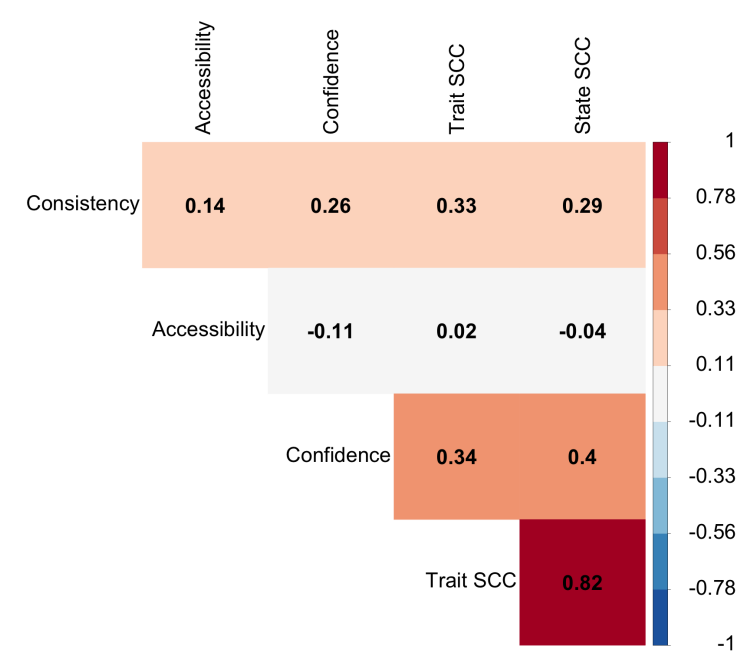

Figure 2

Study 2: Consistent with Study 1, both state and trait selfconcept clarity (SCC) were associated with confidence and consistency of me/not me trait judgments. Accessibility was not significantly associated with any variables. 


\section{Regressions}

Furthermore, we examined the independent effects of confidence and consistency on both trait and state self-concept clarity using hierarchical regression analyses. In step one of this model, we found that the linear model predicting trait self-concept clarity with confidence and consistency was significant $(F(2,236)=25.44), p<.001)$, and both confidence and consistency were significant predictors (see Table 2). In step two, we added state self-concept clarity as a third predictor to determine whether confidence and consistency explained unique variance over state self-concept clarity. The model was significant, and adding state self-concept clarity increased model fit to a large degree $(F(3,235)=165.21$, $p<.001)$. As expected, state self-concept clarity was a strong predictor of trait self-concept clarity; however, even after controlling for this association, the effect of consistency on trait self-concept clarity remained significant. The effect of confidence was no longer significant (Table 2).

We also conducted the same analyses on state self-concept clarity as the outcome. The model in step one was significant $(F(2,236)=28.08, p<.001)$, and confidence and consistency were both significant predictors (Table 2). In step two of this model, we included trait self-concept clarity as a third predictor to determine whether confidence and consistency explained unique variance over trait self-concept clarity. The model was significant, and adding trait self-concept clarity increased model fit to a large degree $(F(3,235)=169.70$, $p<.001)$. As expected, trait self-concept clarity was a strong predictor of state self-concept clarity, but even after controlling for this association, the effect of confidence on trait self-concept clarity remained significant. The effect of consistency was no longer significant (Table 2).

\section{Discussion}

These results replicate the findings from Study 1. Even with the $3 \mathrm{~s}$ timer for the me/not me task, accessibility remained weakly correlated with the other focal variables. This may indicate that participants may be quick in selecting "me" or "not me," but these response may be inaccurate, and speed does not always entail clarity. The state self-concept clarity measure had high internal reliability $(\alpha=0.89)$ even with accessibility items; however, we decided to no longer measure response times in our following study since the consistency and confidence components capture self-concept clarity better than accessibility.

\section{Part Two: A Comparison Approach to Self-Concept Clarity}

\section{Study 3: Integrative Data Analysis}

Using the updated me/not me task and the new state selfconcept clarity scale from Studies 1 and 2, Study 3 explored whether temporal comparisons influence state self-concept clarity. In this study, we performed an integrative data analysis on two combined samples (more details in the Method section to follow).

People engage in temporal comparisons in order to gain crucial information about the self; however, the outcomes of these comparisons depend on whether people are focused on differences or similarities over time (see Albert, 1977; Peetz and Wilson, 2013; M. Ross and Wilson, 2003; A. E. Wilson and Ross, 2001). In this study we look at whether the type of temporal comparison, and the consequence of those comparisons on self-evaluations, influence people's self-concept clarity. Using a paradigm from previous temporal self-appraisal research (2021), participants engaged in a temporal comparison between the past and present self, but were randomly assigned to evaluate either their past self (relative to the present) or their present self (relative to the past). Additionally, they were randomly assigned to focus on either similarities or differences when comparing their past and present selves. If people feel most clear about themselves when living in accordance with the lay theories about positive change and stability over time, then we should find that self-concept clarity is highest (a) when unique attributes of the past self are rated more negatively, (b) when unique attributes of the present self are rated more positively, and (c) when shared attributes between the past and present selves are rated more positively. In other words, we hypothesized that self-concept clarity would be highest for participants who engaged in a comparison that highlighted either positive change (improvement) or positive stability.

\section{Method \\ Participants and Design}

Data was combined from two samples which were originally treated as Studies 3 and 4. In Sample 1, an exploratory three-way interaction was found, and Sample 2 was a preregistered study designed to replicate the effect. However, given the large sample size requirements for detecting a three-way interaction, we decided to combine the two samples to test the preregistered three-way interaction. The results of each individual sample are reported in the Supplementary Materials (https:/osf.io/vume3/?view_only= a710851d4c2e407bb0397a4fc1834b8f). The combined sample consisted of 799 participants $\left(M_{\text {age }}=31.78, S D_{\text {age }}=\right.$ $12.15,43 \%$ male) from the United States who participated on Prolific Academic for at least minimum wage. After providing consent, participants were randomly assigned to one of the four conditions in a Target $\times$ Comparison betweensubjects experiment.

\section{Target manipulation}

In the Present condition, participants were asked to spend a few moments thinking about "how your self now is related to your self from the past." In the Past condition, participants were asked to spend a few moments thinking about "how your self from the past is related to your self now." The crucial difference between these conditions is which self serves as the target of comparison, or the self to be evaluated. Partic- 
Table 2

Study 2: Regression Coefficients and Significant Tests for Hierarchical Regressions Predicting Self-Concept Clarity (SCC)

\begin{tabular}{|c|c|c|c|c|c|c|c|c|c|c|}
\hline Outcome & Model & $R^{2}$ & Predictor & $\beta$ & $\begin{array}{c}\beta \\
95 \% \mathrm{CI}\end{array}$ & $b$ & $S E$ & $\begin{array}{c}b \\
95 \% \mathrm{CI}\end{array}$ & $t$ & $p$ \\
\hline \multirow[t]{9}{*}{ Trait SCC } & Model 1 & 0.18 & & & & & & & & \\
\hline & & & Intercept & & & 0.39 & 0.40 & {$[-0.41,1.18]$} & & \\
\hline & & & Confidence & 0.27 & {$[0.15,0.39]$} & 0.43 & 0.10 & {$[0.24,0.63]$} & 4.40 & $<.001$ \\
\hline & & & Consistency & 0.26 & {$[0.14,0.38]$} & 1.38 & 0.32 & {$[0.74,2.02]$} & 4.25 & $<.001$ \\
\hline & Model 2 & 0.68 & & & & & & & & \\
\hline & & & Intercept & & & -0.04 & 0.25 & $[-0.54,0.46]]$ & & \\
\hline & & & Confidence & 0.00 & {$[-0.08,0.08]$} & 0.00 & 0.04 & {$[-0.13,0.13]$} & -0.06 & .952 \\
\hline & & & Consistency & 0.11 & {$[0.03,0.18]$} & 0.57 & 0.21 & {$[0.16,0.98]$} & 2.74 & $<.001$ \\
\hline & & & State SCC & 0.79 & {$[0.71,0.87]$} & 0.82 & 0.04 & {$[0.73,0.90]$} & 19.13 & $<.001$ \\
\hline \multirow[t]{9}{*}{ State SCC } & Model 1 & 0.19 & & & & & & & & \\
\hline & & & Intercept & & & 0.53 & 0.39 & {$[-0.23,1.28]$} & & \\
\hline & & & Confidence & 0.35 & {$[0.23,0.46]$} & 0.53 & 0.09 & {$[0.35,0.72]$} & 5.69 & $<.001$ \\
\hline & & & Consistency & 0.19 & {$[0.07,0.31]$} & 0.99 & 0.31 & {$[0.38,1.60]$} & 3.20 & $<.001$ \\
\hline & Model 2 & 0.68 & & & & & & & & \\
\hline & & & Intercept & & & 0.24 & 0.24 & {$[-0.24,0.71]$} & & \\
\hline & & & Confidence & 0.14 & {$[0.06,0.21]$} & 0.21 & 0.06 & {$[0.09,0.33]$} & 3.46 & $<.001$ \\
\hline & & & Consistency & 0.00 & {$[-0.08,0.07]$} & -0.04 & 0.20 & {$[-0.43,0.36]$} & -0.18 & .856 \\
\hline & & & Trait SCC & 0.77 & {$[0.69,0.85]$} & 0.74 & 0.04 & {$[0.67,0.82]$} & 19.13 & $<.001$ \\
\hline
\end{tabular}

ipants were then asked to list four attributes in four separate text boxes that describe the target self in terms of similarities or differences.

\section{Comparison manipulation}

In the Similarities condition, participants were instructed to describe attributes of the target self that are shared with the standard. In the Differences condition, they were instructed to describe attributes of the target self that are unique to that self, or not shared with the standard. For instance, those in the Present Differences condition were prompted with the question: "What attributes do you have now that you do not share with your self from the past?"

\section{Measures}

After completing the attribute listing task, participants were shown the four attributes they had typed previously and were instructed to rate the valence of each one on a 7-point scale $(1=$ extremely negative, $7=$ extremely positive; $\alpha=0.83$ ). Next, participants completed the me/not me task with identical 40 attributes (20 pairs of opposites) as in Studies 1 and 2. As before, we used the me/not me task to measure self-concept consistency and confidence ( $\alpha=0.94)$. Participants then completed the 10-item state self-concept clarity measure from Studies 1 and 2 using a 5-point scale ( $1=$ strongly degree; $5=$ strongly agree; $\alpha=0.91$ ). After completing the tasks, participants read a debriefing statement and exited the study.

\section{Results}

One hundred and fifty-three participants were excluded from the data analyses for failing the manipulation and attention checks. Therefore, the trimmed sample consisted of 646 participants $\left(M_{\text {age }}=32.00, S D_{\text {age }}=12.32,42 \%\right.$ male $)$. We tested our hypotheses using a multiple regression analyses treating Target, Comparison, and attribute ratings as predictors of state self-concept clarity, consistency, and confidence. A dummy-code representing the sample (Sample $2=$ 1) was also included as a co-variate to account for any differences in mean levels of the focal outcome variables across samples. We focused specifically on the predicted threeway interaction but all statistical results in the full model can be found in the Online Supplement (https://osf.io/vume3/ ?view_only=a710851d4c2e407bb0397a4fc1834b8f).

\section{State self-concept clarity}

The predicted three-way interaction of Ratings $\times$ Target $\times$ Comparison was significant on self-concept clarity (see Figure 3). Thus, we focused on decomposing this interaction using both the Johnson-Neyman technique to examine significance regions, as well as a simple slopes analyses.

Significance regions. We first used the Johnson-Neyman approach to examine at what level of attribute ratings the Target effect (Past vs. Present) is significant, within each Comparison (Similarity vs. Difference) condition. In the Differences condition, the effect of Target was significant $(p<.05)$ when attribute ratings were outside of the interval $[4.13,5.35]$, revealing a crossover interaction between 

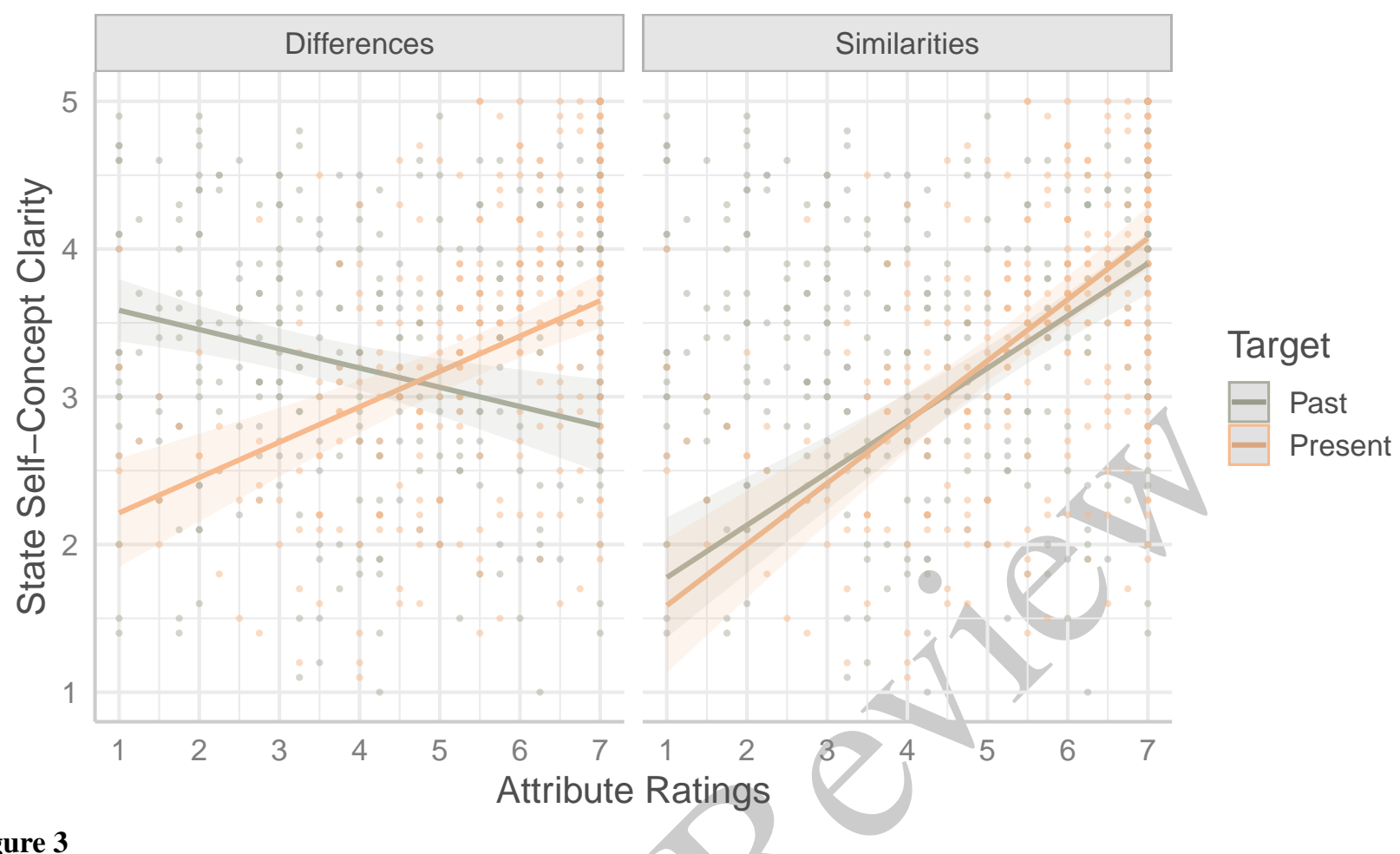

Figure 3

Study 3: State self-concept clarity was positively associated with attribute ratings in all conditions except when thinking about past differences. When past differences are more positive, self-concept clarity suffers.

Target $\times$ Comparison when focused on differences. Specifically, self-concept clarity was highest for participants whose unique past (vs. present) attributes were more negative, and whose unique present (vs. past) attributes were more positive (see Figure 3, left panel). However, in the Similarities condition, the effect of Target was not significant at any level of attribute ratings ( $p s>.25$; Figure 3 , right panel).

Simple slopes. To explore effects of ratings within the Target and Differences conditions, we examined simple slopes. When focused on similarities, participants with more positive attribute ratings reported higher state self-concept clarity in both the Past $(\beta=0.70, S E=0.09, t(637)=7.85, p<.001)$ and Present conditions $(\beta=0.82, S E=0.10, t(637)=8.25$, $p<.001)$. Thus, self-concept clarity increases as shared attributes between the past and present selves become more positive (i.e., positive stability; Figure 3, right panel).

When focused on differences, self-concept clarity increased as attribute ratings increased in positivity, but only in the Present condition $(\beta=0.47, S E=0.08, t(637)=6.14$, $p<.001)$. When considering differences, self-concept clarity decreased with the positivity of attribute ratings in the Past condition $(\beta=-0.26, S E=0.07, t(637)=3.47, p<.001)$. Thus, self-concept clarity increases as unique attributes of the past or present self signal positive change (i.e., improve- ment; Figure 3, left panel).

\section{Consistency}

We carried out the same analyses with consistency as the outcome variable, and the three-way interaction was significant (Figure 4), so we focused on decomposing this interaction using Johnson-Neyman and simple slopes analyses.

Significance regions: In the Differences condition, the slope of Target was significant $(p<.05)$ when attribute ratings were outside of the interval [3.40 5.51], again revealing a crossover interaction between Target $\times$ Comparison (Figure 4 , left panel. However, in the Similarities condition, there were no significant effects of Target ( $p s>0.86$; Figure 4, right panel).

Simple slopes: When focused on similarities, participants with more positive attribute ratings displayed higher consistency in both the Past $(\beta=0.37, S E=0.10, t(636)=3.82$, $p<.001)$ and Present conditions $(\beta=0.30, S E=0.08$, $t(636)=3.51, p<.001)$. Thus, consistency increases as shared attributes between the past and present selves become more positive (Figure 4, right panel).

When focused on differences, consistency increased as attribute ratings increased in positivity, but only in the Present condition $(\beta=0.30, S E=0.08, t(636)=3.51, p<.001)$. When considering differences, consistency decreased with 

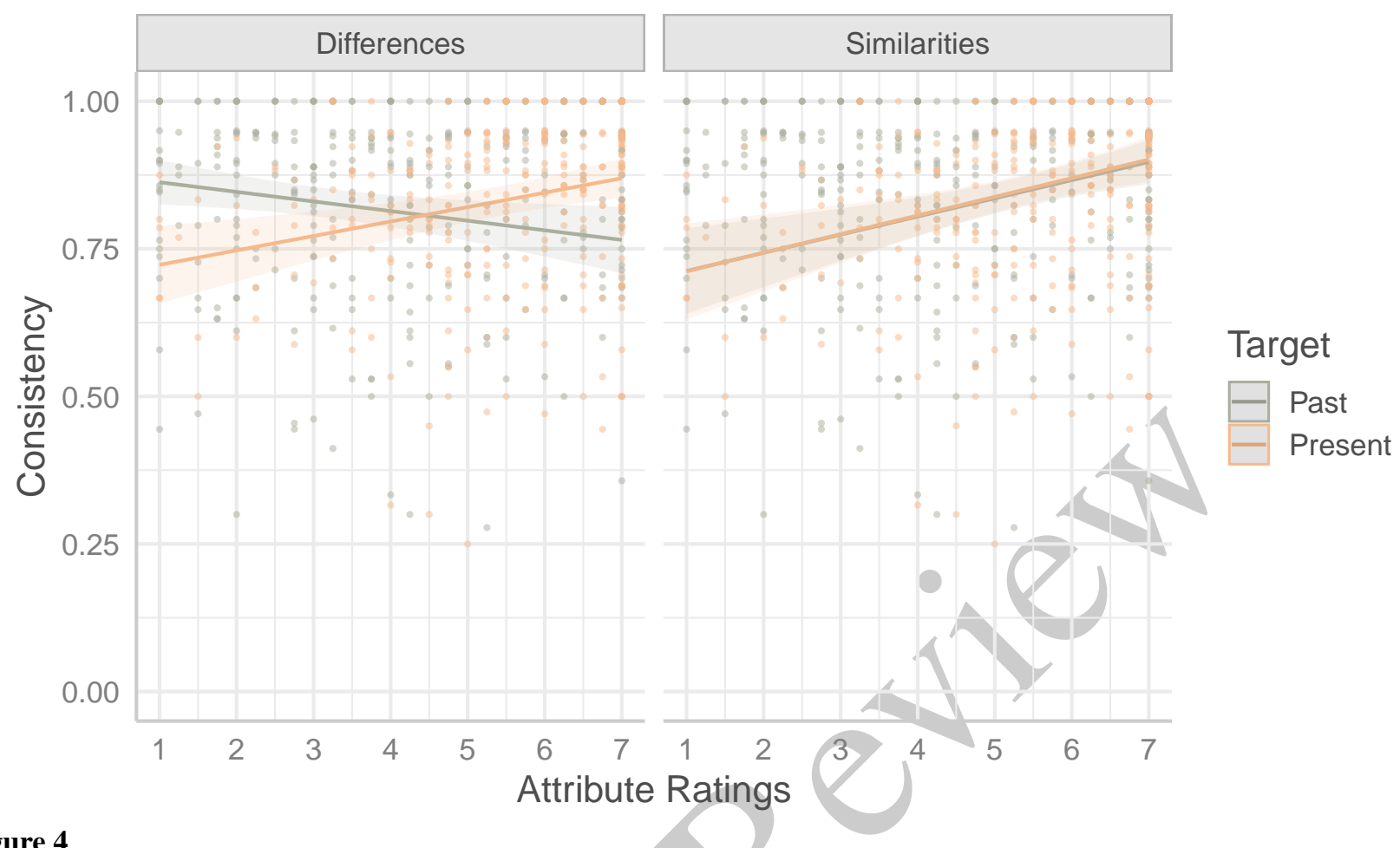

Figure 4

Study 3: Similar to state self-concept clarity, consistency was positively associated with attribute ratings in all conditions except when thinking about past differences.

the positivity of attribute ratings in the Past condition $(\beta=$ $-0.20, S E=0.08, t(636)=-2.43, p=.02)$. Thus, consistency increases as unique attributes of the past or present self signal positive change (Figure 4, left panel).

\section{Confidence}

The three-way interaction for confidence was not significant $(p=.88)$, so we did not explore this further.

\section{Discussion}

In Study 3, our hypotheses regarding state self-concept clarity were mostly supported. We found support for a threeway interaction between attribute ratings, Target, and Comparison in predicting state self-concept clarity and consistency of self-evaluations during a me/not me task. Because attribute ratings moderated the effects of Target and Comparison on these two measures of self-concept clarity, this finding suggests that people's desire to conform to particular ways of self-development over time influences self-concept clarity more than self-continuity more broadly. When thinking about similarities, self-concept clarity is positively associated with positive attribute ratings for both the past and present selves, suggesting that stability is primarily related to self-concept clarity to the extent that shared attributes have a positive valence. However, we find novel evidence that self- change can also influence self-concept clarity in both negative and positive ways. When self-change is upward, people feel that they know themselves better. However, if change is downward, people report lower clarity about who they are. If self-concept clarity was about self-continuity more generally, we would expect self-concept clarity to be higher when thinking of similarities, and lower when thinking about differences, regardless of the implications of those comparisons for the self. Instead, clarity comes when temporal comparisons reveal that ones self is developing along common narratives that cast the self in a positive light (improvement and positive stability).

The three-way interaction was not significant with regard to confidence. Further examination of this outcome suggests that there is a similar pattern of slopes, such that confidence is higher when temporal comparisons produce positive evaluations of the self. We return to this topic in the General Discussion.

\section{General Discussion}

The main goals of our research were to (1) develop a set of measures to assess state self-concept clarity and (2) to use those measures to better understand how self-concept clarity is influenced by temporal comparison. In Studies 1 and 2, we 
expanded on previous research that employed a me/not me task (Campbell, 1990), which demonstrated that participants with high self-concept clarity provided quick, consistent, and confident responses in their self-attribute judgments. Our research slightly diverges from this past work by specifically investigating how these components are associated with trait and state self-concept clarity. Our results suggested that trait self-concept clarity was more strongly associated with consistency and state self-concept clarity was more strongly associated with confidence. Accessibility-or the speed of participants' responses-was not associated with any of the other self-concept clarity measures, which is inconsistent with past research. In both Study 1 and 2, we found that inter-correlations among confidence, consistency, trait, and state self-concept clarity were strong, lending strong support for the convergent validity of these measures.

Using these new measures, we found in Study 3 that selfconcept clarity is influenced by the evaluative implications of temporal self-comparisons, which highlight the importance of holding a positive view of the present self, rather than a generally consistent self-view, for gaining clarity about oneself. Although past literature claims that self-concept stability is one of the components of self-concept clarity (Campbell et al., 1996; Wu et al., 2010), our findings suggest that focusing on similarities between the past and present self can be negative if those similarities are also negative. Alternatively, we find that focusing on differences-or discontinuity-between the past and present selves can be positive for self-clarity as long as those differences signal selfimprovement. Taken together, the current research modifies the definition of self-concept clarity and explores how it is affected by comparing oneself over time.

\section{Implications for Temporal Comparison and Self-Concept Clarity}

There is no doubt that people have the desire to know who they are. Developing a personal identity is crucial throughout one's life, which is evident in Erikson's psycho-social developmental stages (Cote and Levine, 1987). It is also important to note that one of the challenges in building a strong, clear sense of self is that people are constantly changing. Although previous studies have shown that self-concept clarity declines with drastic life changes, such as romantic relationship breakups and role exits, these events are often accompanied with emotional distress and social isolation (Light and Visser, 2013; Slotter et al., 2010). Our findings suggest that change should not affect one's self-concept clarity to the extent that the change is in the direction of growth or improvement. Indeed, this perspective is supported by previous research showing that self-concept clarity can be higher when starting a new chapter in life, namely during role entries and the first semester of college, which were associated with positive emotions (Light and Visser, 2013; Shin et al., 2016).

There are at least a few explanations for why self-concept clarity is associated with evaluations that signal positive growth or stability over time. First, self-concept clarity may be a defense that prevents negative traits from integrating into our core self-concept. Similar to a self-serving bias, in which one takes credit for positive outcomes and attributes negative events to external factors (Shepperd et al., 2008), it is possible that people believe that only their positive traits are who they "really are" and thus feel clear about who they are when focused on those positive traits. When made aware of one's negative attributes, people may begin to question their core selves, as these attributes do not fit with people's generally positive views of themselves, or with their positive ideal selves (Higgins, 1987, 1989). Future research could explore whether self-concept clarity is higher for people who have generally negative self-views and are also made aware of their negative attributes. In the same vein as self-verification theory (Swann et al., 2012), it may be the case that people feel clear about who they are so long as their momentary selfevaluations fit with their global self-views, even if those evaluations are negative. The findings that show a strong link between self-concept clarity and positive self-regard may simply reflect a world in which most people are good most of the time (Alves et al., 2017a), and thus most people know who they are when they fit with this ecological reality.

Along these lines, it is possible that self-concept clarity is thus an emergent property of temporal self-evaluations that confirm existing lay theories about how the self develops over time. The narrative identity approach suggests that people find their identity and a sense of coherence through self-narrative accounts, specifically those that reveal insight into the main character (McAdams, 2006; Thorne et al., 2004). When viewing our lives as a narrative, thinking about uniquely negative aspects of our past selves could lead to greater present self-concept clarity because we enjoy hearing self-redemption stories, which validate the idea of personal growth over time. Although a focus on differences over time could also indicate a lack of stability of the self, the transition to a more positive version of oneself gives crucial insight regarding one's developmental track. If, however, a temporal self-comparison makes salient ways that one has declined, people may question why their lives are not conforming to common lay theories of growth and redemption. If individuals have the tendency to reconstruct their past to make the present self seem more favorable (A. E. Wilson and Ross, 2000, 2001, 2003), it seems likely that people will have a difficult time making sense of why their present self has become worse than their past self. Future research will benefit by exploring how people's lay theories about change and stability over time influence their self-concept clarity. And given that there may be cultural, generational, and even age differences regarding these lay theories (e.g., people may expect decline as opposed to improvement in very late life; see 2021), research on self-concept clarity should examine these 
potential moderators and boundary conditions.

\section{Addressing Null Results for Accessibility and Confidence}

Regarding accessibility, our results did not support our hypothesis that individuals with high self-concept clarity will provide faster responses on the me/not me task. We did not find any statistically significant results in its association with trait and state self-concept clarity along with how it is affected by temporal self-comparisons. Similar to a previous study (Campbell, 1990), we measured accessibility by recording the response times in which a participant selects "me" or "not me" for a given attribute. In such a study, it was found that those with high self-esteem (who were considered to have high clarity) had faster response times (Campbell, 1990), but we did not replicate this result even when placing constraints on participants response times. It is possible that a more precise response time measure is needed to reliably assess this component of self-concept clarity (e.g., mouse-tracking; Mathur and Reichling, 2019). The rate of responses also could have been influenced by factors outside of our control, such as the use of a touch pad, which would be controlled if the studies were conducted in the laboratory instead of online. However, it may also be the case that accessibility of me/not me judgments is not a core component of self-concept clarity. A quick judgment on a me/not me decision could just as plausibly indicate a lack of self-insight, or a defensive response when faced with a decision about one's potentially negative traits, for instance. Future work should clarify the association between accessibility of selfknowledge content and self-concept clarity.

We also failed to find support for a three-way interaction between attribute ratings, Target, and Comparison on confidence in Study 3, despite confidence being associated with self-concept clarity in Studies 1 and 2. This lack of support for the three-way interaction is likely due to differences in the simple slopes of ratings on confidence for the past self $(\beta=0.49)$ and the present self $(\beta=0.79)$ when focused on similarities. Unlike the results for state self-concept clarity and consistency in Study 3, the pattern of slopes on confidence suggest that people may feel a slight boost in clarity when focused on negative aspects of the past self, even if they are shared with the present self. In other words, people may feel confident about their negative past-attributes because the past-self should be negative (Baldwin et al., 2021; A. E. Wilson and Ross, 2001), but simultaneously lack confidence in those attributes when they are shared with the present self, because people also expect to improve (O'Brien and Kardas, 2016). It is worth mentioning that the cross-over interaction found for state self-concept clarity and consistency in the Differences condition was also found for confidence judgments in the Difference condition (see the Online Supplement, Figure 1). So temporal comparisons may indeed influence confidence in self-knowledge particularly when focused on differences, but future research is needed to confirm this possibility.

\section{Limitations}

It is important to note that our findings were based on the responses of participants in the U.S. with English as their first language. Thus, the generalizability of our findings is unknown since we obtained data from a WEIRD sample (Henrich et al., 2010). The lay theories of the self (e.g., improvement over time) could merely be a Western concept, and high state self-concept clarity may not always require a positive present-self. Also, stability could play a more significant role than improvement or positive valence in cultures that value self-continuity over improvement and change. Additional cross-cultural research or use of more diverse samples is required to determine whether our findings extend beyond our limited Western sample.

Another limitation with this research is that we rely on self-reports of self-concept clarity, as well as participants' judgments about a limited number of pre-selected traits. People tend to have fairly limited self-insight (Nisbett and Wilson, 1977), and thus items that ask participants to report on that level of insight about attributes that may or may not be relevant to them are flawed. Future research would benefit from developing other measures that allow participants to generate their own self-related content, and that could then be used to supplement self-reports. For instance, participants could be asked to generate their own traits that could then be used on a me/not me task which makes use of mouse tracking. Confidence, for instance, could be modeled as the extent to which mouse movements waiver between options, as opposed to self-reported confidence about those me/not me judgments. Additionally, participants could be asked to generate features of their self-concepts, such as traits or values, before organizing those features in a multidimensional space according to their similarity (i.e., Spatial Arrangement; Koch et al., 2020). Data from these spatial arrangements could then be analyzed with network analyses and combined with self-reports to better understand how the structure of selfknowledge, which may not be completely accessible to individuals, is associated with the feeling of self-concept clarity. Similar approaches have been applied recently to the study of "attitude networks" and show great promise for modeling complex psychological constructs (Dalege et al., 2017).

\section{Conclusion}

In order for us to understand who we are in the present, we often look to the past. However, we also use the past and present to predict how we will end up in the future. Despite a long tradition of narrative approaches to the self, very little is known about the ways that comparing oneself over time influences the extent to which we develop a feeling of self-concept clarity. Our research presents a first look at this connection between temporal comparison and self-concept clarity, and it opens the door to further theorizing about how knowing who we are is related to how we see ourselves as an 
unfolding self over time.

\section{References}

Albert, S. (1977). Temporal comparison theory. American Psychologist, 84(9), 485-503. https://doi.org/10. 1037/h0021465

Alves, H., Koch, A., \& Unkelbach, C. (2017a). The 'common good' phenomenon: Why similarities are positive and differences are negative. Journal of Experimental Psychology: General, 146(4), 512-528. https : //doi.org/10.1037/xge0000276

Alves, H., Koch, A., \& Unkelbach, C. (2017b). Why good is more alike than bad: Processing implications. Trends in Cognitive Sciences, 21(2), 69-79.

Baldwin, M., Alves, H., \& Unkelbach, C. (2021). A cognitive-ecological approach to temporal selfappraisal. psyarxiv.com/f69dq

Bluck, S., Alea, N., Habermas, T., \& Rubin, D. C. (2005). A tale of three functions: The self-reported uses of autobiographical memory [Publisher: Guilford Press]. Social Cognition, 23(1), 91-117. https://doi.org/10. 1521/soco.23.1.91.59198

Campbell, J. D. (1990). Self-esteem and clarity of the selfconcept. Journal of personality and social psychology, 59(3), 538.

Campbell, J. D., Trapnell, P. D., Heine, S. J., Katz, I. M., Lavallee, L. F., \& Lehman, D. R. (1996). Selfconcept clarity: Measurement, personality correlates, and cultural boundaries. Journal of Personality and Social Psychology. https://doi.org/10.1037/ 0022-3514.70.1.141

Cote, J. E., \& Levine, C. (1987). A formulation of erikson's theory of ego identity formation. Developmental review, 7(4), 273-325.

Dai, H., \& Li, C. (2019). How experiencing and anticipating temporal landmarks influence motivation [Publisher: Elsevier]. Current Opinion in Psychology, 26, 44-48. https :// doi .org/10 .1016/J . COPSYC. 2018.04.012

Dalege, J., Borsboom, D., van Harreveld, F., \& van der Maas, H. L. (2017). Network analysis on attitudes: A brief tutorial. Social psychological and personality science, 8(5), 528-537.

Festinger, L. (1954). A theory of social comparison processes. Human Relations, 7(2), 117-140. https :// doi.org/10.1177/001872675400700202

Henrich, J., Heine, S. J., \& Norenzayan, A. (2010). The weirdest people in the world? Behavioral and Brain Sciences, 33(2-3), 61-135.

Higgins, E. T. (1987). Self-discrepancy: A theory relating self and affect [ISBN: 1939-1471]. Psychological Review, 94(3), 319.
Higgins, E. T. (1989). Self-discrepancy theory: What patterns of self-beliefs cause people to suffer? [ISBN: 0065-2601]. Advances in experimental social psychology, 22, 93-136.

Jetten, J., Haslam, S. A., Cruwys, T., Greenaway, K. H., Haslam, C., \& Steffens, N. K. (2017). Advancing the social identity approach to health and wellbeing: Progressing the social cure research agenda. European Journal of Social Psychology, 47(7), 789-802.

Jetten, J., Haslam, S. A., \& Haslam, C. (2012). The case for a social identity analysis of health and well-being. The social cure: Identity, health and well-being, 319.

Kahneman, D., \& Miller, D. T. (1986). Norm theory. comparing reality to its alternatives. Psychological Review, 93(2), 136-153. https ://doi . org/10 . 1037/0033 295X.93.2.136

Koch, A., Speckmann, F., \& Unkelbach, C. (2020). Qspam: How to efficiently measure similarity in online research. Sociological Methods $\mathcal{E}$ Research, 0049124120914937.

Light, A. E., \& Visser, P. S. (2013). The ins and outs of the self: Contrasting role exits and role entries as predictors of self-concept clarity. Self and identity, 12(3), 291-306.

Markus, H., \& Nurius, P. (1987). Possible selves: The interface between motivation and the self-concept. Self and identity: Psychosocial perspectives (pp. 157172). John Wiley \& Sons.

Mathur, M. B., \& Reichling, D. B. (2019). Open-source software for mouse-tracking in qualtrics to measure category competition. Behavior Research Methods, 51(5), 1987-1997.

McAdams, D. P. (2001). The psychology of life stories [Publisher: SAGE Publications Inc]. Review of General Psychology, 5(2), 100-122. https://doi.org/10.1037/ 1089-2680.5.2.100

McAdams, D. P. (2006). The problem of narrative coherence. Journal of Constructivist Psychology, 19(2), 109125. https://doi.org/10.1080/10720530500508720

McAdams, D. P. (2008). Dan p. McAdams, 2008 [Section: 8]. In John, Robins, \& Pervin (Eds.), Handbook of personality: Theory and research2 (3rd ed., pp. 242-262). Guilford Press.

McAdams, D. P., \& McLean, K. C. (2013). Narrative identity. Current Directions in Psychological Science. https://doi.org/10.1177/0963721413475622

McAdams, D. P., \& Pals, J. L. (2006). A new big five: Fundamental principles for an integrative science of personality [ISBN: 1935-990X Publisher: US: American Psychological Association]. American psychologist, 61(3), 204-217. 
Molouki, S., \& Bartels, D. M. (2017). Personal change and the continuity of the self. Cognitive Psychology, 93, 1-17. https://doi.org/https://doi .org/10.1016/j. cogpsych.2016.11.006

Nisbett, R. E., \& Wilson, T. D. (1977). Telling more than we can know: Verbal reports on mental processes [ISBN: 1939-1471(Electronic),0033295X(Print) Place: US Publisher: American Psychological Association]. Psychological Review, 84(3), 231-259. https :// doi . org/10 . 1037/0033 295X.84.3.231

O'Brien, E., \& Kardas, M. (2016). The implicit meaning of (my) change. https://doi.org/10.1037/pspi0000073

Peetz, J., \& Wilson, A. E. (2013). The post-birthday world: Consequences of temporal landmarks for temporal self-appraisal and motivation. [ISBN: 19391315(Electronic),0022-3514(Print) Place: US Publisher: American Psychological Association]. Journal of Personality and Social Psychology, 104(2), 249-266. https://doi.org/10.1037/a0030477

Pronin, E., \& Ross, L. (2006). Temporal differences in trait self-ascription: When the self is seen as an other [Publisher: US: American Psychological Association]. Journal of Personality and Social Psychology, 90(2), 197-209. https :// doi .org/10.1037/0022 3514.90.2.197

Ricoeur, P. (1991). Narrative identity. Philosophy today, 35(1), 73-81.

Ross, M., \& Wilson, A. E. (2000). Constructing and apprasing past selves. Memory, brain, and belief (pp. 231258). Harvard University Press.

Ross, M., \& Wilson, A. E. (2003). Autobiographical memory and conceptions of self [Publisher: SAGE PublicationsSage CA: Los Angeles, CA]. Current Directions in Psychological Science, 12(2), 66-69. https: //doi.org/10.1111/1467-8721.01228

Ryff, C. D. (1989). Happiness is everything, or is it? explorations on the meaning of psychological wellbeing. Journal of Personality and Social Psychology, 57(6), 1069-1081.

Ryff, C. D. (1991). Possible selves in adulthood and old age: A tale of shifting horizons. [Publisher: American Psychological Association]. Psychology and aging, 6(2), 286.

Sedikides, C., Wildschut, T., Cheung, W. Y., Hepper, E. G., Vail, K., Brackstone, K., Routledge, C., Arndt, J., Zhou, X., \& Vingerhoets, A. J. (2016). Nostalgia fosters self-continuity: Uncovering the mechanism (social connectedness) and consequence (eudaimonic well-being). Emotion. https://doi.org/10. 1037/emo0000136
Sharma, S., \& Sharma, M. (2010). Self, social identity and psychological well-being. Psychological Studies, 55(2), 118-136.

Shepperd, J., Malone, W., \& Sweeny, K. (2008). Exploring causes of the self-serving bias. Social and Personality Psychology Compass, 2(2), 895-908.

Shin, J. Y., Steger, M. F., \& Henry, K. L. (2016). Self-concept clarity's role in meaning in life among american college students: A latent growth approach. Self and Identity, 15(2), 206-223.

Slotter, E. B., Gardner, W. L., \& Finkel, E. J. (2010). Who am i without you? the influence of romantic breakup on the self-concept. Personality and social psychology bulletin, 36(2), 147-160.

Smith, K. E. (2010). Meaning, subjectivity, society: Making sense of modernity. Brill.

Suddendorf, T., \& Busby, J. (2003). Mental time travel in animals? Trends in Cognitive Sciences, 7(9), 391-396. https://doi.org/10.1016/S1364-6613(03)00187-6

Swann, W. B., Jetten, J., Gómez, Ã., Whitehouse, H., \& Bastian, B. (2012). When group membership gets personal: A theory of identity fusion [ISBN: 19391471 (Electronic)\$backslash\$r0033-295X (Linking)]. Psychological Review, 119(3), 441-456. https://doi.org/10.1037/a0028589

Taylor, S. E., Wayment, H. A., \& Carrillo, M. (1996). Social comparison, self-regulation, and motivation. In R. M. Sorrentino \& E. T. Higgins (Eds.), Handbook of motivation and cognition (pp. 3-27). Guilford Press.

Thorne, A., McLean, K. C., \& Lawrence, A. M. (2004). When remembering is not enough: Reflecting on self-defining memories in late adolescence. Journal of Personality, 72(3), 513-542.

Unkelbach, C., Koch, A., \& Alves, H. (2019). The evaluative information ecology: On the frequency and diversity of "good" and "bad". European Review of Social Psychology, 30(1), 216-270. https://doi.org/10. 1080/10463283.2019.1688474

Wilson, A. E., \& Ross, M. (2000). The frequency of temporal-self and social comparisons in people's personal appraisals [ISBN: 0022-3514]. Journal of Personality and Social Psychology, 78(5), 928-942. https://doi.org/10.1037/0022-3514.78.5.928

Wilson, A. E., \& Ross, M. (2001). From chump to champ: People's appraisals of their earlier and present selves. Journal of Personality and Social Psychology, 80(4), 572-584. https://doi.org/10.1037/00223514.80.4.572

Wilson, A. E., \& Ross, M. (2003). The identity function of autobiographical memory: Time is on our side [Publisher: Taylor \& Francis Group]. Memory, 11(2), 137-149. https://doi.org/10.1080/741938210 
Wu, J., Watkins, D., \& Hattie, J. (2010). Self-concept clarity: A longitudinal study of hong kong adolescents. Personality and Individual Differences, 48(3), 277282.

Zhang, Y., \& Chen, M. (2018). Character strengths, strengths use, future self-continuity and subjective well-being among chinese university students. Frontiers in Psychology, 9, 1040. https://doi.org/10.3389/fpsyg. 2018.01040 